\title{
"Os homens que sabem": as mulheres da Cooperativa de Jaguarão e as matemáticas
}

\author{
"The Men who Know": \\ the Women of the Jaguarão Cooperative and the Mathematics
}

\author{
Talita Mendes de Araujo ${ }^{1}$ \\ Marta Cristina Cezar Pozzobon ${ }^{2}$
}

\begin{abstract}
Resumo
Neste artigo, discutimos sobre a matemática escolar e o uso das diferentes matemáticas, tendo como objetivo identificar a relação das mulheres da Cooperativa de Aliança Solidária e Prestadora de Serviços (COOADESPS) do município de Jaguarão/RS com o trabalho e com o uso das matemáticas. Para dar conta de tal objetivo, realizamos uma pesquisa qualitativa, com observações e entrevistas semiestruturadas com três mulheres cooperadas e com o coordenador da Cooperativa. O material foi analisado a partir dos seguintes referenciais: Wittgenstein (1979); Gottschalk (2014); Knijnik, Wanderer, Giongo e Duarte (2013); Walkerdine (2007); entre outros. Os materiais foram organizados em três grupos de recorrências: "As mulheres da Cooperativa", "Alguns usos da matemática pelas mulheres" e "Os homens (...) que sabem". Consideramos que o uso das matemáticas pelas mulheres da Cooperativa estava relacionado ao sustento da sua família, ao salário, ao preço do gás, ou melhor, aos usos próprios do seu grupo de convivência.
\end{abstract}

Palavras-chaves: Mulheres da Cooperativa; Matemática Escolar; Usos das Matemáticas.

\section{Abstract}

In this article, we discuss the school mathematics and the use of different mathematics, with the objective of identifying the relationship of women from the Cooperative of Solidarity Alliance and Service Provider (COOADESPS) of the city of Jaguarão/RS to the work and use of mathematics . To meet this goal, we conducted a qualitative research, with observations and semi-structured interviews with three cooperative women and with the Cooperative coordinator. The material was analyzed from the following references: Wittgenstein (1979); Gottschalk (2014); Knijnik, Wanderer, Giongo e Duarte (2013); Walkerdine (2007); among others. The materials were organized into three groups of recurrences: "The Women of the Cooperative," "Some Uses of Mathematics by Women," and "Men ... who Know." We considered that the use of mathematics by the women of the Cooperative was related to the sustenance of their family, to the salary, to the price of gas, or rather, to the proper uses of their coexistence group.

Keywords: Women of the Cooperative. School Mathematics. Uses of Mathematics.

\footnotetext{
${ }^{1}$ Licenciada em Pedagogia pela Universidade Federal do Pampa - UNIPAMPA/Jaguarão, Brasil. Email: talitamendesa@hotmail.com

${ }^{2}$ Doutora em Educação, pela Universidade do Vale do Rio dos Sinos - UNISINOS, docente do curso de Pedagogia na Universidade Federal do Pampa - UNIPAMPA/Jaguarão, Brasil. Email: marta.pozzobon@hotmail.com
} 


\section{Introdução}

A cultura é uma produção humana, um conjunto de mitos, valores, estilo, conhecimento e normas de conduta, portanto a língua também é uma expressão da cultura, específica de cada grupo, e que se constitui como um instrumento de comunicação falada ou escrita. Cada língua funciona dentro do que Wittgenstein (1979, p. 23) chama de jogos de linguagem, como destacamos: "Chamarei de 'jogos de linguagem' o conjunto da linguagem e das atividades com as quais está entrelaçada. O termo 'jogo de linguagem' é uma parte de uma atividade ou de uma forma de vida". As formas de interpretar estes jogos de linguagem estão incorporadas aos modos de agir e pensar dos sujeitos nos contextos de prática ou nas diferentes formas de vida.

De acordo com Gottschalk (2014, p. 77), “(...) as palavras são utilizadas numa infinidade de maneiras diferentes e aparentadas umas com as outras de diversos modos. Não há algo comum a todas as aplicações de uma palavra que nos daria a sua essência”. Em cada cultura existem matemáticas ${ }^{3}$ que apresentam jogos de linguagem distintos, que podem ser entendidos dentro de seus contextos. Isso nos leva a ponderar a existência de outras matemáticas, além da matemática acadêmica, que por muito tempo foi considerada a única a ser aceita e valorizada.

A perspectiva da etnomatemática questiona o modelo que destaca a existência de uma Matemática, e, principalmente das ideias que defendem a matemática acadêmica como universal e como rainha das ciências. Com esta perspectiva, que “(...) visa explicar os processos de geração, organização e transmissão de conhecimento em diversos sistemas culturais e as forças interativas que agem entre os processos" (D’Ambrosio,1990, p. 7), que se discute a existência de diferentes matemáticas, como a existência de diferentes culturas.

Neste sentido, a perspectiva da etnomatemática valoriza as construções matemáticas de diferentes comunidades como a matemática produzida no dia a dia, para que homens e mulheres entendam e produzam modos de lidar com as suas necessidades. A matemática acadêmica passa a ser uma das "matemáticas" com seus fins e situações específicos, porém sem valorizar uma matemática em detrimento das outras. As outras matemáticas, que são situadas em um contexto histórico e social, como a matemática de pescadores, de vendedores, de donas de casas, produzem significados matemáticos específicos que trazem semelhanças de famílias entre si. Wittgenstein (1979) diz que existe “(...) semelhança entre os usos de palavras ou conceitos, não por sua posse comum de características essenciais ou definidoras, mas por uma relação geral de similaridade entre os diferentes usos".

A partir de tais ideias e do interesse das pesquisadoras, deu-se a escolha do tema: as mulheres da COOADESPS ${ }^{4}$ e a matemática escolar. Este artigo atravessa três linhas da

\footnotetext{
3 Optamos pelo uso da grafia em minúsculo da palavra matemáticas, pois nos referimos às diferentes matemáticas: a matemática acadêmica, a matemática escolar e outras (Knijnik, Wanderer, Giongo \& Duate, 2013). Quando nos referirmos à Matemática como única e universal, usamos a grafia da primeira letra em maiúscula.
}

${ }^{4}$ Cooperativa de Aliança Solidaria e Prestadora de Serviços.

Zetetiké, Campinas, SP, v.25, n. 3, set./dez.2017, p.405-417 
DOI: http://dx.doi.org/10.20396/zet.v25i3.8648207

vivência como acadêmica de uma das autoras: o trajeto como bolsista do PIBID ${ }^{5}$, as inquietações como mulher e o projeto de pesquisa $^{6}$, no qual atuou como bolsista de iniciação científica. No início da graduação, uma de nós teve a oportunidade de realizar um trabalho na COOADESPS como bolsista do PIBID, que mesmo não envolvendo os/as catadores/as e outros/as colaboradores/as, objetivava a separação de livros em um ambiente externo ao galpão, mas teve em vários momentos contato com os/as trabalhadores/as, levando a conhecer um pouco da história, tanto do lugar, como daqueles/as que ali trabalhavam. O recorte dos sujeitos da pesquisa vem das inquietações ao longo do curso de graduação sobre o lugar da mulher na sociedade, sua representatividade e como o machismo ${ }^{7}$ afeta as relações em diversos ambientes. A escolha pela área de educação matemática é devido à formação escolar e às reflexões como bolsista de pesquisa.

Salientamos que, de acordo com o Atlas de Economia Solidária no Brasil (Brasil, 2006, p. 11), “a Economia Solidária é compreendida como um conjunto de atividades econômicas - de produção, distribuição, consumo, poupança e créditos - organizadas e realizadas solidariamente por trabalhadores e trabalhadoras sob a forma coletiva e autogestionária”. Com isso, compreendemos que existem aproximações entre a educação matemática e a economia solidária, principalmente como aborda Meneghetti (2013, p. 56), pelas aproximações com o "[...] Programa Etnomatemática, pois este visa a entender a realidade dentro de um contexto cultural".

A partir disso, neste artigo, pretendemos identificar a relação das mulheres da COOADESPS com o trabalho e com o uso das matemáticas. Trazemos alguns apontamentos e discussões sobre as matemáticas, a constituição de jogos de linguagens e as semelhanças de família. Mostramos os caminhos metodológicos, descrevendo os materiais e os instrumentos de pesquisa. $\mathrm{Na}$ parte das análises, consideramos as mulheres da cooperativa e as matemáticas a partir de três grupos de recorrência: "As mulheres da Cooperativa"; "Alguns usos da matemática pelas mulheres" e "Os homens (...) que sabem”.

\section{Discussões teóricas}

Nesta parte, trazemos algumas discussões a respeito da matemática escolar, das outras matemáticas e do conceito de jogos de linguagem propostos por Wittgenstein (1979). Isso nos possibilitará a problematização da(s) matemática(s) produzidas por mulheres da cooperativa de Jaguarão. Trazemos as contribuições, principalmente de Knijnik, Wanderer, Giongo e Duarte (2013) e Wittgenstein (1979) que abordam conceitos que se aproximam desta investigação.

\footnotetext{
${ }^{5}$ Programa de bolsas de iniciação à docência, subprojeto Pedagogia.

${ }^{6} \mathrm{O}$ projeto de pesquisa discute sobre a docência contemporânea para ensinar matemática nos anos iniciais.

${ }^{7}$ Referimo-nos aos valores patriarcais que privilegiam a figura do homem em detrimento da mulher, ou melhor dito, do “(...) regime da dominação-exploração das mulheres pelos homens” (SAFFIOTI, 2004, p. 44).
} 
DOI: http://dx.doi.org/10.20396/zet.v25i3.8648207

De acordo com Velho e Lara (2011, p. 4), existe a diferenciação da Matemática como ciência formal e rigorosa e o conjunto de habilidades práticas necessárias à sobrevivência advindas da matemática informal. Como dizem, existe diferenças entre

[...] a Matemática formal ou acadêmica, ensinada e aprendida nas escolas, e a Matemática informal, praticada por grupos culturais delimitados (sociedades tribais nacionais, crianças de certa faixa etária, classes profissionais, etc.). Trata-se, respectivamente, do conhecimento matemático trabalhado na sala de aula (legitimado) e do conhecimento matemático produzido fora da escola (não legitimado) (VELHO; LARA, 2011, p. 4).

Como afirma Lizcano (2004, p. 125), “[a]s práticas matemáticas dos outros ficam assim legitimadas - ou deslegitimadas - em função de sua maior ou menor parecença com a matemática que aprendemos nas instituições acadêmicas". Isso nos ajuda a afirmar que existem diferentes matemáticas, cada uma produzida em um contexto diferente, entendida a partir de seu espaço, de seus contextos e de seus falantes. Com isso, concordamos com Wanderer (2007, p. 163) ao apontar que

(...) no caso das linguagens matemáticas, se poderia afirmar que a geração de seus significados é dada por seus diversos usos, produzidos 'ao sabor das circunstâncias', sendo um deles aquele que conforma a matemática acadêmica, outro, a matemática escolar e outros, ainda, aqueles que produzem as muitas matemáticas camponesas, indígenas, etc.

Tais ideias em relação as diversas matemáticas se aproximam do estudado por Wittgenstein (1979) como jogos de linguagem. O autor diz que "Chamarei de 'jogo de linguagem' o conjunto de linguagem e das atividades com as quais está entrelaçada. $\mathrm{O}$ termo 'jogo de linguagem' deve aqui salientar que o falar da linguagem é uma parte da atividade ou de uma forma de vida (Wittgenstein, 1979, p. 23).

Cada matemática, então, constitui um jogo de linguagem diferente, que apresenta semelhanças de família com as outras matemáticas. De acordo com Wittgenstein (1979), cada jogo de linguagem apresenta semelhanças entre os usos de palavras e de conceitos, afastandose das concepções essencialistas, que propõem a relação entre significado e palavra ou significado e objeto empírico. Para o autor,

Ao invés de indicar algo que seja comum a tudo o que chamamos linguagem, digo que não há uma coisa sequer que seja comum a estas manifestações, motivo pelo qual empregamos a mesma palavra para todas, - mas são aparentadas entre si de muitas maneiras diferentes. Por causa deste parentesco, ou destes parentescos, chamamos todas de "linguagens" (Wittgenstein, 1979, § 65, grifos do autor).

Com isso, consideramos que as diferentes formas de vida produzem matemáticas diversificadas, questionando a "universalidade da Matemática produzida pela academia, salientando que esta não é universal, na medida em que não é independente da cultura" (Knijnik,Wanderer, Giongo \& Duarte, 2013, p. 24). Isso nos leva a supor que a forma de vida das mulheres da cooperativa está ligada com as práticas vivenciadas pelas cooperadas, questionando as ideias que ligam o papel da mulher na aprendizagem da matemática escolar ao "sucesso em raciocinar", em que a "Matemática é vista como desenvolvimento da mente". Nesta perspectiva, as meninas são consideradas capazes de "fazer Matemática”, de nível 
DOI: http://dx.doi.org/10.20396/zet.v25i3.8648207

inferior, mas os meninos “(...) tendem a produzir evidência sobre o que é considerado 'razão', mesmo que seu próprio desempenho possa ser considerado pobre" (Walkerdine, 2007, p. 12).

O desempenho das meninas na matemática, entendida como o desenvolvimento da mente, de desenvolver o raciocínio lógico, produziria problemas em relação ao lugar da mulher, pois presumiria a existência de uma única matemática, a escolar. Souza e Fonseca (2010) abordam que homens e mulheres têm produzido o discurso da superioridade masculina em relação à matemática e da dificuldade das mulheres em lidar com tais situações. Como abordam as autoras, na escola perpetua-se a ideia que defende a matemática como o desenvolvimento do raciocínio, aproximando as situações matemáticas do desenvolvimento da razão, que "[...] reativa[m] o aparecimento do enunciado de que "Homem é melhor em matemática do que mulher'" (Souza \& Fonseca, 2010, p. 605). Esses discursos de superioridade masculina para matemática produzem discursos que desvalorizam a capacidade da mulher de gerenciamento de sua profissão e da sua vida.

\section{Caminhos metodológicos}

Destacamos que esta pesquisa tem um cunho qualitativo e parte da análise das interações sociais, levando em conta a relação estabelecida entre o sujeito e os contextos de prática, que no caso envolve as cooperadas e o coordenador. Para Kauark, Manhães e Medeiros (2010, p. 28), o levantamento de dados "[...] envolve a interrogação direta das pessoas cujo comportamento se deseja conhecer". Diante disso, partimos da observação etnográfica do espaço da cooperativa, do conhecimento dos sujeitos e dos usos que fazem das matemáticas.

Observações etnográficas envolvem uma abordagem que centraliza suas preocupações em compreender o que de fato seus membros precisam saber, fazer, prever e interpretar a fim de participar na construção dos eventos em andamento da vida que acontece dentro do grupo social estudado por meio da qual o conhecimento cultural se desenvolve (Green; Dixon \& Zaharlick, 2005, p. 18).

Diante disso, consideramos a interação com o espaço da pesquisa, na perspectiva de entender os discursos em relação às matemáticas. Os registros foram anotados em um diário de campo, desenvolvido pela observação nos espaços da cooperativa, para observar todos os processos que envolvem os usos da(s) matemática(s) pelas mulheres. Além do diário de campo, usamos como instrumento de pesquisa uma entrevista semiestruturada ${ }^{8}$, que foi organizada de forma a contemplar, além do ambiente de trabalho, a estrutura familiar e escolarização das três mulheres cooperadas, que são nossos sujeitos da pesquisa, além do coordenador da cooperativa. As entrevistas foram gravadas e transcritas. Para identificar as mulheres usaremos nomes fictícios, como: Maria, Joana e Carla e o coordenador, que será identificado deste modo. O coordenador foi entrevistado, para que entendêssemos sobre a fundação da Cooperativa, a quantidade de pessoas que trabalham neste espaço, o papel da mulher na Cooperativa.

\footnotetext{
${ }^{8}$ Chamamos de conversa daqui em diante no texto, pois foram realizadas com as três cooperadas, para que se sentissem à vontade. Salientamos que apenas três mulheres trabalham na Cooperativa.
} 
DOI: http://dx.doi.org/10.20396/zet.v25i3.8648207

O diário de campo se constituiu a partir das visitas realizadas em horários variados, que aconteceram no segundo semestre de 2015, em diferentes dias da semana. Escolhemos este tipo de visita, para que pudéssemos observar como se constituía a rotina de trabalho das cooperadas. No dia da apresentação da pesquisadora, a Cooperativa estava quase vazia, além das cooperadas, poucos homens se encontravam no galpão, o que possibilitou ter uma conversa com elas sobre o que faziam, bem como conversar sobre a pesquisa que estávamos desenvolvendo. Em um próximo dia, percebemos um certo receio de uma das cooperadas com a presença da pesquisadora, o que levou as cooperadas a optarem por realizar a conversa no horário em que estariam em almoço.

Nos dias em que fomos ao galpão conversar com as cooperadas, havia muito movimento, pois nestes dias havia o recebimento e o carregamento de materiais para separação. Isso possibilitou estar todo o tempo com as cooperadas, já que estas trabalham apenas na esteira que está alocada ao fundo no galpão. A conversa foi realizada na cozinha, um espaço que as cooperadas organizaram dentro do galpão para fazerem as refeições e descansarem no horário disponível para o almoço.

Quanto ao espaço ocupado pelas mulheres na Cooperativa, observamos que conta apenas com um espaço onde a cooperadas ficam no canto direito ao fundo, cercado de sacos com os materiais para serem separados. Todo o galpão dispõe destes mesmos sacos, ficando vago apenas um canto direito próximo a entrada, que é onde colocam o que já foi separado e prensado. Há apenas uma cozinha improvisada que tem um pequeno fogão, alguns utensílios e algumas poltronas, espaço utilizado pelas mulheres e uma sala ao lado do galpão que é ocupado pelos homens no horário do almoço. O espaço é pequeno e muito tumultuado.

A Cooperativa foi fundada no ano de 2003, após o decreto que proibiu o trabalho dentro dos lixões, que era onde as famílias do bairro Imba ${ }^{9}$ tiravam seu sustento. "Essas famílias ficariam desempregadas e foi daí que surgiu a ideia, a necessidade de se ter uma cooperativa, porque um catador só não pode receber ajuda, mas onde um grupo organizado com CNPJ seguindo as regras, ai a gente tem como celebrar contrato com a Prefeitura, como receber pelo que faz" (coordenador da cooperativa).

Como disse o coordenador, foi a partir da necessidade de emprego dos moradores que surgiu a Cooperativa, que trabalha hoje em regime de colaboração com a prefeitura, prestando serviços de limpeza urbana, o que ajuda no salário dos cooperados, porém essa não é uma realidade desde a sua criação, pois como conta o coordenador: "Nós fundamos a cooperativa e tivemos dois anos sem poder trabalhar, porque na época o gestor não apoiava a cooperativa, aí quando trocou a gestão do município aí foi quando foram nos ajudar, e conseguimos trabalhar".

A partir das conversas e anotações no diário de campo, organizamos alguns quadros para perceber algumas recorrências sobre o dito em relação ao trabalho e ao uso das

\footnotetext{
${ }^{9}$ Bairro no qual a cooperativa está atualmente localizada.
} 
DOI: http://dx.doi.org/10.20396/zet.v25i3.8648207

matemáticas. Isso nos levou a organizar a próxima seção, que trata sobre "As mulheres da Cooperativa"; "Alguns usos da matemática pelas mulheres" e "Os homens (...) que sabem".

\section{As mulheres da Cooperativa e as matemáticas}

De acordo com as discussões que estamos propondo, destacamos que não podemos analisar a linguagem desatrelada do meio em que o sujeito está inserido, por isso, nesta parte, trazemos um pouco das observações realizadas na Cooperativa, para contextualizar de quais matemáticas falamos, quem são seus usuários e quem são estas cooperadas. Apresentamos as análises do material investigado, que foi separado a partir das nossas análises, levando em conta que não conhecemos os sujeitos e seus jogos de linguagem sem conhecer o espaço em que estão inseridos, por isso trazemos "As mulheres da Cooperativa", que nos possibilita explanar quem são essas mulheres, suas condições de vida e percepções de seu trabalho. A partir disso, os usos da matemática, considerando o item: "Alguns usos da matemática pelas mulheres", em que mostramos a relação das mulheres com a matemática. Para finalizar, trazemos o que ficou evidente no material analisado, que se refere às relações de trabalho dentro da Cooperativa e aos usos da matemática escolar pelas mulheres: "Os homens (...) que sabem".

\section{As mulheres da Cooperativa}

As mulheres que participaram da pesquisa são: Maria ${ }^{10}$ de 57 anos; Joana de 59 anos; e Carla de 68, todas com o Ensino Fundamental incompleto, sendo que Maria foi a única a cursar a modalidade de Educação de Jovens e Adultos. Estas mulheres residem nas regiões periféricas da cidade de Jaguarão/RS. Criaram ou criam seus filhos e netos e encontraram na Cooperativa uma forma de sustentar suas famílias. Carla começou na Cooperativa há 7 (sete) anos, quando perdeu o marido e precisou de um emprego. Joana trabalha na Cooperativa há 3 anos, tendo começado a trabalhar depois que foi demitida de uma loja. Já Maria é uma sócia fundadora, que trabalhava no lixão da cidade, de onde surgiram as primeiras aspirações à fundação deste espaço.

No município, a organização na forma de Cooperativa é recente (sete anos), podendo justificar o reduzido número de mulheres que se envolvem neste trabalho. Como aponta o coordenador da Cooperativa: "Nós somos 53, sendo que 53 entre limpeza urbana e coleta seletiva. Aqui somos 16, agora nós somos 3 que estão retirados por questões de saúde. São só 3 mulheres, mais $4^{11}$ de lá são 7”.

De acordo com o Instituto de Pesquisa Econômica e Aplicada - IPEA, os catadores e as catadoras de materiais recicláveis têm se organizado, para "reverter a situação de exclusão

\footnotetext{
${ }^{10}$ A pedido das cooperadas, a entrevista foi realizada em trio e Maria foi a que se sentiu mais à vontade para falar, muitas vezes Joana e Carla apenas concordavam com ela, por isso, aparece em muitos momentos os recortes com as falas de Maria. ${ }^{11}$ As quatro mulheres destacadas pelo coordenador trabalham na limpeza urbana e não foram consideradas nesta
pesquisa.
} 
DOI: http://dx.doi.org/10.20396/zet.v25i3.8648207

social em suas diversas dimensões (...) vêm buscando se articular coletivamente com base em diferentes formatos organizacionais (...)" (IPEA, 2013, p. 19). Tais ideias corroboram com a iniciativa de organização da Cooperativa em Jaguarão/RS, que de acordo com o coordenador: "Essa fundação foi assim, na época o, então Leonir Calvete que era líder do bairro Imbá, nós tínhamos problemas no lixão há muito tempo atrás. Eu já tinha trabalhado com o lixão. Aí se deu por decreto do Ministério Público que era obrigado a tirar todo o povo que trabalhava lá. Aí a gente teve o pessoal que na época não trabalhava lá (...), essas famílias ficariam desempregadas. Foi daí que surgiu a ideia, a necessidade de se ter uma cooperativa, porque um catador só não pode, assim um catador não pode receber ajuda, mas onde um grupo organizado com CNPJ seguindo as regras (...). Aí a gente tem como celebrar contrato com Prefeitura, como receber pelo que faz".

Diante disso, as três mulheres passam o dia todo no galpão, por questões de deslocamento, distância da Cooperativa as suas residências. Neste espaço realizam o trabalho de segregação, que constitui na separação dos materiais recebidos pela Cooperativa. Como diz uma cooperada: "A gente separa: lixo, garrafa, lata colorida, branco, papel, nylon. A gente separa, recicla, né”. (Maria).

Em relação ao que recebem pelo seu trabalho, quando questionadas se é o suficiente para sustentar sua família, uma cooperada se refere que o objetivo da Cooperativa "é gerar emprego e renda para quem não tem oportunidade, pessoas que estão analfabetas [...], a gente não tem problema com idade, sexo, cor, religião" (Maria). Destacam que apesar de não ganharem muito, “(...) é melhor do que a gente se encostar, porque se a gente se encostar não vai conseguir... A gente tá doente, ela tem problema [se refere a Joana], ela tem problema de coluna [se refere a Carla], eu tenho problema no pulmão, mas tem que trabalhar, porque receber um salário só de encostada aí não dá mesmo, aí é a mesma coisa que receber só o contrato ${ }^{12}$, aqui pelo menos tem as cargas para ajudar”. (Maria). As cooperadas relatam que muitas mulheres já trabalharam neste espaço, mas que "não gostam, vem pra ganhar dinheiro, acham pouco e vão embora". (Maria) Ou se cansam, "tem dias que até a gente se cansa" (Carla) e, então, muitas preferem trabalhar em outro espaço da Cooperativa, na limpeza urbana. As cooperadas, por vezes, até questionam os discursos produzidos pela Cooperativa, pelos contextos que estão inseridas, mas, ao mesmo tempo, são constituídas por este "jogo complexo e instável que envolve enfrentamentos, invenções, produções" (Souza, 2008, p. 108).

Portanto, com a descrição, destacamos um pouco das dificuldades que passam estas mulheres no espaço de trabalho, como chegaram até o galpão da Cooperativa, mostrando que cada uma tem uma história de vida diferente, mas que todas estão neste lugar por razões sociais, de exclusão do mercado de trabalho, de dificuldades financeiras ou por outras razões. Mas, por outro lado, elas têm a clareza da importância do que fazem para a limpeza da

${ }^{12} \mathrm{O}$ contrato se refere a um acordo entre a Cooperativa e Prefeitura, para que a Cooperativa trabalhe na limpeza urbana e a Prefeitura pague aos cooperados/as um salário fixo e equipamentos para tal serviço. 
DOI: http://dx.doi.org/10.20396/zet.v25i3.8648207

cidade, das ruas, do planeta, como diz uma cooperada: "Isso desentope os bueiros, tudo e não morremo afogado”. (Maria). Porém, mesmo que sejam discutidas questões ambientais na atualidade, somos, ainda, levados a não respeitar aqueles/aquelas que sobrevivem do lixo, das atividades que envolvem a coleta, a separação e a reciclagem.

\section{Alguns usos da matemática pelas mulheres}

Quando chegamos ao espaço da Cooperativa, tínhamos um objetivo de pesquisa, que era identificar os jogos de linguagens produzidos pelas mulheres cooperadas e as semelhanças de família que estes poderiam ter com a matemática escolar, porém chegando lá percebemos que as cooperadas não se envolviam com questões ligadas ao dinheiro ou que envolvessem o processo de produção e venda de materiais. Fomos para campo, supondo que as mulheres calculavam os seus lucros, o quanto recebiam, como acontecem nos "problemas" propostos pela matemática escolar. A partir disso, percebemos pelas falas das mulheres, que faziam outros usos da matemática, principalmente nas situações que precisavam se entender a respeito do que necessitavam para o seu sustento. Uma cooperada destaca: "dizer que ganha bem, tá mentindo, ganha, né, da Prefeitura 600, 500. As cargas, às vezes, dá 200 e pouco, 300 e assim vai, é o que dá né, mas dá pelo menos. Se a gente se encostar vai ganhar menos ainda, não vai dar". (Maria). E, ainda, acrescenta outras questões ligadas ao contrato que a Cooperativa tem com a Prefeitura do município: "um pouco é bom, o gás pelo contrato, quando falta o gás se a gente ligar pra lá, levam o gás. Se ficar sem dinheiro, fica sem gás né, e assim não, a gente trabalhando tem... (...) Mas se na hora a gente não tem dinheiro fica sem o gás para comer, aí tendo contrato a gente só liga e eles levam e depois descontam, mais caro, mas descontam. Agora subiu né, ficou mais carinho, a gente acostumou já”. (Maria).

Percebemos aqui a matemática do cotidiano, pautada nas necessidades das cooperadas em manter o lar, as despesas da casa, que é o mais próximo de alguma matemática que elas mostraram no período da pesquisa. Como coloca Knijnik, Wanderer, Giongo e Duarte (2013, p. 71), “(...) a matemática aparece com objetivos, papeis, funções, e práticas diferentes daquelas que assume na prática escolar", como percebemos nas falas das cooperadas, assumindo um papel próprio de seu cotidiano, para resolver os problemas de subsistência.

\section{"Os homens (...) que sabem"}

Percebemos que as mulheres se distanciam do trabalho e da matemática, quando o assunto é o rateio do dinheiro conseguido com as cargas. Colocam que "os homens lá que sabem" (Maria), "nós mulheres não sabemos nada" (Joana). Acrescentam que "Eles vêm, eles pesam e depois recebem e vêm cá e dividem com nós a quantidade que deu pra nós, mas saber tá lá dentro” (Maria) e “(...) se eles chegarem com um real é um real que a gente tem que pegar" (Carla).

De acordo com as falas acima, parece haver uma diferenciação do serviço da mulher, sendo ela mais apta ao cuidado dos outros, das tarefas que não envolvem a matemática e o homem parece que fica responsabilizado pelas tarefas que exigem tomar decisões quanto ao pagar, a quantidade de dinheiro cada um/a precisa receber. Isso nos leva a discutir que a 
DOI: http://dx.doi.org/10.20396/zet.v25i3.8648207

mulher é, muitas vezes, concebida como o sujeito em falta, como o sujeito irracional, incapaz de aprender e lidar com a matemática, pois isso seria produzido pelos homens (Walkerdine, 2007).

Esses enunciados que circulam em nossa cultura, nos modos como nos organizamos e vivemos as nossas vidas, como mulheres e homens, em arranjos sociais - que se configuram mais vantajosos para os homens do que para as mulheres - são constantemente reativados, em discursos de diversos campos sendo apresentados como se fizessem parte da natureza feminina e da natureza masculina (Souza, 2008, p. 129, grifos do autor).

São estes enunciados que percebemos na fala do coordenador quando coloca sobre a participação das mulheres, dizendo que tem determinados trabalhos que elas não conseguem fazer, pois “(...) sentíamos, por exemplo, agora mesmo a gente estava carregando, a gente não pode colocar de repente uma menina a fazer força com um fardo de 300 quilos, não que ela não tenha capacidade, ela tem mais aí a gente optou" (Coordenador). Este discurso usado pelo coordenador encontra "(...) um denominador comum, para diversas formas de subordinação feminina, nos fatos de que as mulheres têm a capacidade para dar à luz e de que os homens têm uma força muscular superior" (Scott, 1995, p. 75).

Tais ideias, também, são discutidas por Souza (2008), ao trazer que em uma razão cartesiana, homens e mulheres são considerados como sujeitos de natureza diferenciada, que são constituídos a partir de um modelo do "sujeito universal", de preferência "autônomo, racional, consciente e masculino" A partir disso, produzem-se sujeitos com identidades fixas, sujeito masculino e sujeito feminino, que lidam com a matemática de modo diferenciado, o homem como sujeito racional, afastado de emoções e a mulher não racional, preocupada com as atividades do cuidar, de limpar, de separar materiais.

Desse modo, percebemos que as mulheres não se envolvem com o trabalho de logística e venda. Este trabalho é realizado pelos colaboradores, os homens que decidem, que partilham o dinheiro, não estando presente nenhuma das mulheres da Cooperativa. Diante disso, uma cooperada diz "que isso [as transações de venda de material] quem faz são eles, a gente não sabe, o que eles disserem que deu, deu, a gente só sabe que é bastante” (Joana).

Tanto cooperadas como coordenador relatam que, desde a constituição da Cooperativa, houve uma maior presença de mulheres em determinados momentos, mas que recentemente a presença delas vem diminuindo, como aponta uma cooperada: "Só no começo que tinha a mesma coisa, depois sempre foi mais homem do que mulheres, agora mesmo só pegam homem porque só continua nós 3, já entrou uns quantos" (Maria). Quando questionadas o porquê isso estaria ocorrendo, dizem: "Elas não gostam, só a gente fica" (Joana); "as outras que tinham, foram para a limpeza urbana que é da mesma coisa. Por que não gostam, vem pra ganhar dinheiro, acham pouco e vão embora" (Carla).

O coordenador traz a preocupação de aumentar o espaço para as mulheres na Cooperativa, mas que isso está atrelado a uma melhor condição de trabalho "precisaremos agregar mais pessoas e queremos colocar mais mulheres, mas, também, queremos uma estrutura diferenciada. Nos nossos galpões, a gente quer ter sabe, um alojamento, vestiário 
DOI: http://dx.doi.org/10.20396/zet.v25i3.8648207

separado". (coordenador). Isso nos remete ao enunciado que aponta a fragilidade feminina, como um ser a ser "cuidado", "fisicamente frágil” (Souza, 2008, p. 206).

\section{Algumas considerações finais}

Diante da pesquisa, ao chegar à Cooperativa, concebíamos que o trabalho era desenvolvido de modo coletivo, supondo que todos sabiam e faziam uso das diferentes matemáticas implicadas neste contexto, mas, para a nossa surpresa, nos deparamos com um cenário muito diferente. Neste espaço, encontramos apenas três mulheres, senhoras, trabalhando em um canto do galpão, sozinhas, enquanto vários homens corriam de um lado para o outro, emitindo notas, carregando caminhões. E durante o desenvolvimento da investigação, surpreendemo-nos em saber que as mulheres não tinham noção de quanto produziam e que aceitavam o que recebiam, independentemente do valor.

A função daquelas mulheres na Cooperativa era de separadoras de resíduos, segregadas dos outros espaços de produção do galpão, por serem "velhas", "fracas" ou por simplesmente "serem mulheres, precisando ser preservadas". As mulheres não participavam de todos os espaços da Cooperativa, eram pobres e sem muito conhecimento escolar, porém traziam grandes bagagens do grupo de convivência. Criaram filhos, fundaram a Cooperativa, batalharam para estar ali e dar a seus filhos um estudo, mesmo que, como diz uma cooperada: "pra gente não adianta mais" (Maria), referindo-se aos estudos escolares. Estas cooperadas não percebiam a importância dos seus saberes e do trabalho para o andamento da Cooperativa, pois quem decidia e comandava a distribuição dos lucros eram os homens.

Como aponta Walkerdine (2007, p. 8), a produção de verdades sobre as meninas e a Matemática, principalmente em relação ao melhor desempenho dos meninos em detrimento do desempenho inferior das meninas, nos "testes matemáticos" e nas observações em sala de aula, tem produzido discursos de falta, de inferioridade, de insucesso, de aproximação às profissões ligadas aos cuidados. Essas ideias parecem ser reproduzidas nas atividades desempenhadas pelas mulheres na Cooperativa, aproximando-as das tarefas de cuidado e deixando para os homens as tarefas que exigem decisão, distribuição de valores e pagamentos.

A matemática que essas mulheres usavam era a da vida, a do sustento, mesmo sem saber quanto ganhavam, contavam com o mínimo para criar seus filhos e netos. Apenas uma delas frequentou a escola, mesmo que na modalidade EJA e foi desta que tivemos uma maior participação. Percebemos que a matemática usada pelas mulheres se refere aos modos de lidar com as despesas de casa. Isso nos leva a ponderar que esta matemática é organizada a partir de regras próprias, de jogos de linguagem que são instituídos pelo grupo de convivência, a partir dos seus usos e dos significados atribuídos às palavras pelas pessoas. Wittgenstein (1979) nos ensina que existem semelhanças entre as palavras, mas que não existe "uma coisa comum a esses fenômenos, em virtude da qual empregamos a todos a mesma palavra"; o que existe é apenas um parentesco de "uns com os outros de muitos 
DOI: http://dx.doi.org/10.20396/zet.v25i3.8648207

modos diferentes. E por causa desse parentesco ou desses parentescos, chamamo-los todos de 'linguagens"' (WITTGENSTEIN, 1979, p. 38).

Portanto, considerando o que foi possível observar nesta pesquisa, as mulheres se abstêm de mexer com o dinheiro, pegando apenas o que lhes é dado. Observamos, também, no período da pesquisa de campo, que mesmo com a chegada e saída das carretas, em nenhum momento elas foram consultadas ou informadas do peso da carga. Parece que estas informações eram reservadas apenas para os homens, que tinham as notas dos produtos, com controle de peso e valor e, assim, cuidavam da burocracia envolvida no processo de venda. $\mathrm{O}$ uso da matemática pelas mulheres da Cooperativa estava relacionado ao sustento da sua família, ao salário, ao preço do gás, o que nos leva a pensar, de acordo com a perspectiva da etnomatemática, que usavam uma matemática própria do grupo de mulheres, com suas características e peculiaridades.

Em síntese, concluímos que esta pesquisa pode contribuir com a discussão do papel das mulheres em espaços como cooperativas, do uso da matemática escolar e das outras matemáticas como possibilidades de empoderamento dos sujeitos, tanto de mulheres como de homens. Essa discussão pode, também, contribuir para a formação de professores nos cursos de Pedagogia, no sentido de trazer para estudo as outras matemáticas das práticas sociais e a possibilidade de legitimá-las como parte do currículo escolar.

\section{Referências}

Brasil. (2006). Atlas da Economia Solidária no Brasil. Brasília: Ministério do Trabalho e Emprego (MTE). Secretária Nacional de Economia Solidária (SENAES). Disponível em: http://base.socioeco.org/docs/sies_atlas_parte_1.pdf.

D’ambrosio, U. (1990). Etnomátematica. São Paulo: Ática.

Gottschalk, C. M. C. (2014). Fundamentos filosóficos da matemática e seus reflexos no contexto escolar. International Studies on Law and Education, 18, 73-82.

Green, J. L.; Dixon, C. N.; \& Zaharlick, A. (2005). A etnografia como uma lógica de investigação. Educação em Revista, Belo Horizonte, 42, 13-79.

IPEA, Instituto de Pesquisa Econômica Aplicada. (2013). A efetividade da participação social no Brasil. Base de dados. Disponível em <www.ipea.gov.br/participacao> Brasília: Ipea.

Kauark, F., Manhães, F. C., \& Medeiros, C. (2010). Metodologia da pesquisa: guia prático. Itabuna: Via Litterarum.

Knijnik, G., Wanderer, F., Giongo, I. M., \& Duarte, C. G. (2013). Etnomatemática em movimento. Belo Horizonte: Autêntica Editora.

Lizcano, E. (2004). As matemáticas da tribo europeia: um estudo de caso. In: G. Knijnik, F. Wanderer; C. J. Oliveira (org.). Etnomatemática, currículo e formação de professores. (pp. 124-138). Santa Cruz: EDUNISC. 
DOI: http://dx.doi.org/10.20396/zet.v25i3.8648207

Meneghetti, R. C. G. (2013). Educação Matemática e Economia Solidária: Uma aproximação por meio da etnomatemmática. Revista Latinoamercicana de Etnomatemática, 6(1), 4066. Disponível em: http://www.redalyc.org/pdf/2740/274025755002.pdf

Saffioti, H. I. B. (2004). Gênero, patriarcado, violência. São Paulo: Editora Perseu Abramo.

Scott, J.W. (1995). Gênero: uma categoria útil de análise histórica. Educação \& Realidade. Porto Alegre, 20(2), 71-99. Disponível em: http://seer.ufrgs.br/index.php/educacaoerealidade/article/view/71721/40667

Souza, M. C. R. F. (2008). Gênero e matemática(s) - jogos de verdade nas práticas de numeramento de alunas e alunos da educação de pessoas jovens e adultas. Belo Horizonte: Autêntica.

Souza, M. C. R. F.. \& Fonseca, M. C. F. R. (2010). Razão cartesiana, matemática e sujeito olhares foucaultianos. Educação \& Realidade, 35(3), 303-322. Disponível em: http://seer.ufrgs.br/educacaoerealidade/article/view/9437

Velho, E. M. H,. \& Lara, I. C. M. de. (2011). O Saber Matemático na Vida Cotidiana: um enfoque etnomatemático. Revista de Educação em Ciência e Tecnologia, 4(2), 3-30. Disponível

em: https://periodicos.ufsc.br/index.php/alexandria/article/download/37558/28850

Walkerdine, V. (2007). Ciência, razão e a mente feminina. Educação \& Realidade, 32(1), 7 24.

Wanderer, F. (2007). Escola e Matemática Escolar: Mecanismo de Regulação sobre Sujeitos Escolares de uma Comunidade Rural de Colonização Alemã do Rio Grande do Sul. Tese de Doutorado em Educação. São Leopoldo: Universidade do Vale do Rio dos Sinos. Acesso em: 20 de agosto de 2015. Retirado em 20 de agosto, 2015, de: http://biblioteca.asav.org.br/vinculos/tede/escola\%20e\%20matematica.pdf.

Wittgenstein, L. (1979). Investigações Filosóficas. São Paulo: Abril Cultural. 